\title{
Oculomotor and Vestibular Findings in Autosomal Recessive Spastic Ataxia of Charlevoix-Saguenay
}

\author{
J. DIONNE, G. WRIGHT, H.BARBER, R. BOUCHARD AND J.P.BOUCHARD
}

\begin{abstract}
SUMMARY: Electron!'stagmographic recordings were made of oculomotor and vestibular function in 11 patients with autosomal recessive spastic ataxia of Charlevoix-Saguena!: All had horizontal gaze nistagmus, marked impairment of smooth ocular pursuit and optokinetic n!stagmus, and defective fixation suppression of caloric nistagmus. Many had saccadic dismetria, but saccade velocity was probably unaffected. Abnormalties pointing to brainstem disturbance were sparse. The findings are thought to indicate mainly diffuse cerebellar disease, with particular involvement of vermis and vestibulo-cerebellum.
\end{abstract}

RÉSUMÉ: Nous avons évalué sous électrony'stagmographie II patients souffrant d'ataxie spastique familiale de CharlevoixSaguenay. Tous présentaient un nı'stagmus du regard, une poursuite et un nı'stagmus optokinétique sévèrement altérés ainsi qu'un défaut de suppression du n!'stagmus post-calorique. Peu d'anomalies nous ont laissé croire à une atteinte du tronc cérébral. Nous avons pensé que ces divers signes étaient indicatifs d'une lésion cérébelleuse touchant surtout le vermis et le vestibulo-cervelet.
From Le Centre Hospitalier de l'Université Laval, the Dizziness Unit of Sunnybrook Medical Centre. Department of Otolaryngology, University of Toronto. and l'Hôpital de l'Enfant-Jésus, Québec

Reprint requests for the complete supplement on Friedreich's Ataxia (Phase Two, Part Two) to:

Dr. André Barbeau, Clinical Research Institute of Montreal, 110 Pine Avenue West, Montreal, Quebec. Canada, H2W IR7.

\section{INTRODUCTION}

A syndrome of autosomal recessive spastic ataxia with childhood onset has been isolated in the CharlevoixSaguenay region of Quebec. Many of the clinical and biochemical features of this disorder have been described by Bouchard et al (1978). The purpose of this paper is to describe oculomotor and vestibular findings from routine electronystagmographic (ENG) studies performed on some of these patients.

\section{METHODS}

The study population consisted of 11 patients with age range from 17 to 42 , seven female and four male. Eye movements were recorded using an ENG strip chart recorder (Siemens Mingograph 800). Recordings were made of movements of each eye separately and of the two together (bitemporal) in the horizontal axis, and of the right eye alone in the vertical. The following examinations were carried out on each patient: calibration, smooth ocular pursuit, optokinetic function, search for gaze nystagmus, caloric and positions test.

Before each subtest, horizontal and vertical saccadic eye movements were calibrated, separately, so as to write $1 \mathrm{~mm}$. of pen displacement for each $1^{\circ}$ of eye movement in the bitemporal leads, and $0.5 \mathrm{~mm}$. per $1^{\circ}$ for each of the other tracings. The bitemporal and vertical leads were recorded with alternating current, and the monocular horizontal with direct current coupling. The patient gazed alternately, at his own rate, at each of a pair of small red lights located $20^{\circ}$ apart on a white board about 1.5 meters in front as he lay in the caloric test position (CTP - body supine, head flexed $30^{\circ}$ ). Predominantly horizontal smooth pursuit function was tested by having each patient, while seated, visually track a golf ball swinging as a pendulum with a period of 2.3 seconds. Peak velocities slowed from about 55 to about 25 degrees per second as the pendulum lost amplitude. Tests for smooth pursuit in the vertical axis were not made. Optokinetic nystagmus (OKN) was induced and recorded in the dark as the seated patient watched stripes moving on a $3 \times 3$-metre screen nearly 2 meters distant. Stripes were projected from behind the patient's head through a rotating drum in both horizontal and vertical directions, at rates of $20,40,60$, and 80 degrees per second, and were alternately dark (47 $\mathrm{cm}$. wide) and light $(44 \mathrm{~cm}$. wide).

The gaze test was recorded with the patient lying in CTP. The visual targets were different colored markers about 1.5 meters distant, located at gaze center (primary position) and at each of 20,30, and 40 degrees to right and left of center (horizontal axis) and 30 degrees up and down (vertical axis). The patient was asked to fix his gaze on different targets for 30 seconds each. In addition, recordings were made with eyes closed and deviations of 30 degrees only in horizontal and vertical axes. To this end, the patient first gazed at the appropriate spot with eyes open and was then encouraged to keep his eyes in the same position but with lids closed. Tests for rebound nystagmus (Hood et al., 1973) were made on two of the eleven patients.

Recordings were made of each patient's resting state, eyes closed and with mental alerting, and then with eyes open and gaze in the primary position, before caloric testing. Hot caloric tests used as a screening method (Barber et al., 1971) were 
employed in all patients, and supplemented by cool irrigations in two. The water was supplied from controlled-temperature tanks and was run for 30 seconds. Responses were recorded with eyes closed and with suitable mental alerting to about 100 seconds from start of stimulus, and the patient then opened eyes for 10 seconds to fixate the calibration target in gaze center position. Recording then continued with eyes closed, for a varying period, without mental alerting. Five minutes then elapsed before the start of the subsequent test.

Tests for positional nystagmus were made on a tilting table on which the head, neck and body were moved slowly together into eight positions, with eyes closed and mental alerting.

Ocular physical examination was not carried out by the authors. While all patients were cooperative during testing, the physical limitations imposed by their disease made standardization of test procedure imperfect at times.

\section{RESULTS}

The findings are summarized in Tables 1 and 2 .

TABLE I

Oculomotor and Vestibular Tests

\begin{tabular}{|c|c|c|c|c|c|c|c|c|c|c|c|c|c|c|c|c|}
\hline \multirow[b]{3}{*}{$\mathbf{P}$} & \multirow[b]{3}{*}{ Sex } & \multirow[b]{3}{*}{ Age } & \multicolumn{6}{|c|}{$20^{\circ}$ Calibration } & \multirow{3}{*}{$\begin{array}{c}\text { Abnormal } \\
\text { Pursuit }\end{array}$} & \multicolumn{4}{|c|}{$\begin{array}{c}\text { Abnormal OKN } \\
\text { (Eye Speed, Slow Phase) }\end{array}$} & \multicolumn{2}{|c|}{ Calorics } & \multirow{3}{*}{$\begin{array}{c}\text { Abnormal } \\
\text { Fixation } \\
\text { Index }\end{array}$} \\
\hline & & & \multicolumn{2}{|c|}{$\begin{array}{c}\text { Fixation } \\
\text { Instability }\end{array}$} & \multicolumn{2}{|c|}{ Overshoot } & \multicolumn{2}{|c|}{ Undershoot } & & \multicolumn{2}{|c|}{$\begin{array}{l}\text { No increase } \\
\text { with stimulus }\end{array}$} & \multicolumn{2}{|c|}{$\begin{array}{c}\text { Sum all } \\
\text { Responses }\end{array}$} & \multirow{2}{*}{$\begin{array}{c}\text { Abnor- } \\
\text { mal }\end{array}$} & \multirow{2}{*}{$\begin{array}{c}\text { Peak } \\
\text { Speeds } \\
2 \text { Hots } \\
\end{array}$} & \\
\hline & & & $\mathbf{H}$ & $\mathbf{v}$ & $\mathbf{H}$ & $\mathbf{v}$ & $\mathbf{H}$ & $\mathbf{V}$ & & $\mathbf{H}$ & $\mathbf{v}$ & $\mathbf{H}$ & $\mathbf{v}$ & & & \\
\hline 1 & $\mathbf{M}$ & 17 & $\mathrm{~F}$ & $\mathrm{~F}$ & + & + & & & + & + & + & $Y$ & $\mathrm{Z}$ & & $\mathrm{Z}$ & + \\
\hline 2 & $\mathbf{M}$ & 22 & $\mathbf{N}$ & - & - & & + & & + & + & + & $\mathbf{Z}$ & $\mathbf{X}$ & & $\mathrm{Y}$ & + \\
\hline 3 & $\mathbf{M}$ & 23 & - & - & + & + & & & + & + & + & $\mathbf{Z}$ & $\mathbf{Y}$ & & $\mathbf{Z}$ & + \\
\hline 4 & $\mathrm{~F}$ & 24 & $\mathbf{N}$ & - & - & $=$ & & & + & + & + & $\mathrm{X}$ & $\mathbf{Z}$ & & $\mathbf{X}$ & + \\
\hline 5 & $\mathrm{~F}$ & 25 & $\mathrm{~F}$ & - & - & & & - & + & + & + & $\mathrm{Y}$ & $\mathbf{Z}$ & & $\mathbf{Y}$ & + \\
\hline 6 & $\mathrm{~F}$ & 30 & $\mathbf{S}$ & - & + & + & + & + & + & + & + & $Y$ & $X$ & & $\mathrm{Y}$ & + \\
\hline 7 & $\mathbf{M}$ & 31 & $\mathrm{~F}$ & - & + & + & + & - & + & + & + & $X$ & $\mathrm{Y}$ & & $\mathbf{Y}$ & + \\
\hline 8 & $\mathrm{~F}$ & 34 & $\mathrm{~F}$ & - & - & + & + & - & + & + & + & Z & $\mathrm{Z}$ & & $\mathrm{X}$ & + \\
\hline 9 & $\mathrm{~F}$ & 34 & $\mathrm{~F}$ & - & - & - & + & + & + & + & + & $\mathrm{Y}$ & $\mathrm{X}$ & & $X$ & + \\
\hline 10 & $\mathrm{~F}$ & 34 & $\mathrm{~F}, \mathrm{~N}$ & - & - & - & & - & + & + & + & $\mathrm{Y}$ & $X$ & & $X$ & + \\
\hline 11 & $\mathbf{F}$ & 42 & $\mathrm{~F}, \mathrm{~S}$ & - & + & - & - & - & + & + & + & $\mathrm{Y}$ & $\mathbf{Z}$ & + & $X$ & + \\
\hline
\end{tabular}

\begin{tabular}{|c|c|c|c|c|c|}
\hline $\begin{array}{l}\text { + Present } \\
\text {-Absent } \\
\text { F Flutter }\end{array}$ & $\begin{array}{l}\text { S } \\
\mathrm{H} \\
\mathrm{V}\end{array}$ & $\begin{array}{l}\text { Square Waves } \\
\text { Horizontal } \\
\text { Vertical }\end{array}$ & $\begin{array}{l}\mathrm{X} \\
\mathrm{Y} \\
\mathrm{Z}\end{array}$ & $\begin{array}{l}\text { Low } \\
\text { Medium } \\
\text { High }\end{array}$ & $\begin{array}{l}\text { This study } \\
\text { population } \\
\text { only }\end{array}$ \\
\hline $\mathrm{N}$ Nystagmic & & & & & \\
\hline
\end{tabular}

TABLE II

Study' of Ny'stagmus

\begin{tabular}{|c|c|c|c|c|c|c|c|c|c|c|c|c|}
\hline \multirow[b]{3}{*}{$\mathbf{P}$} & \multirow[b]{3}{*}{ Sex } & \multirow[b]{3}{*}{ Age } & \multicolumn{5}{|c|}{ Horizontal Nystagmus } & \multicolumn{4}{|c|}{ Vertical Nystagmus } & \multirow{3}{*}{$\begin{array}{c}\text { Nystagmus } \\
\text { in } \\
\text { Centre } \\
\text { Gaze }\end{array}$} \\
\hline & & & \multicolumn{3}{|c|}{ at $30^{\circ}$} & \multirow{2}{*}{$\begin{array}{c}\text { at } 40^{\circ} \\
\text { only, in } \\
\text { one } \\
\text { Direction }\end{array}$} & \multirow{2}{*}{$\begin{array}{l}\text { Abduct- } \\
\text { ing } \\
\text { Eye } \\
\text { Only }\end{array}$} & \multicolumn{2}{|c|}{ Upbeat in } & \multicolumn{2}{|c|}{ Downbeat in } & \\
\hline & & & Bilat & Unilat & None & & & $\begin{array}{c}\text { Lateral } \\
\text { Gaze }\end{array}$ & $\begin{array}{c}\text { Vertical } \\
\text { Gaze }\end{array}$ & $\begin{array}{c}\text { Lateral } \\
\text { Gaze }\end{array}$ & $\begin{array}{c}\text { Vertical } \\
\text { Gaze }\end{array}$ & \\
\hline 1 & $\mathbf{M}$ & 17 & + & & - & - & - & - & - & & & \\
\hline 2 & $\mathbf{M}$ & 22 & + & & & - & - & - & & & & \\
\hline 3 & $\mathbf{M}$ & 23 & + & & - & - & + & - & - & & & \\
\hline 4 & $\mathrm{~F}$ & 24 & + & & - & - & - & - & + & - & & \\
\hline 5 & $\mathrm{~F}$ & 25 & & & + & + & + & - & - & & & \\
\hline 6 & $\mathrm{~F}$ & 30 & & + & & + & - & - & & $=$ & & \\
\hline 7 & $\mathbf{M}$ & 31 & & + & & + & - & - & & + & + & $\mathrm{D}$ \\
\hline 8 & $\mathbf{F}$ & 34 & + & & & - & - & - & & & & \\
\hline 9 & $\mathbf{F}$ & 34 & & + & & - & & - & + & - & & \\
\hline 10 & $\mathrm{~F}$ & 34 & & + & & + & & - & &.- & & \\
\hline 11 & $\mathbf{F}$ & 42 & & + & - & + & - & - & & & & \\
\hline
\end{tabular}




\section{A. Calibration}

All patients could perform horizontal and vertical calibration eye movements, in most cases quite well. Hypometric and/or hypermetric saccades (undershoots and overshoots) were found in horizontal and/or vertical leads in nine of the eleven patients. In the vertical axis, overshoots occurred only on gaze downward (Fig. 1) and a few showed undershoots only on gaze upward. Six of the nine had either or both findings in both horizontal and vertical axes. Blind eyelid movements may have obscured the records in some cases.

A common finding in the recordings was the occurrence of low amplitude, high frequency pen movements at the tops and bottoms of the calibration excursions, as well as elsewhere in the records, even with eyes closed. Examples are shown in Fig. 2. We are uncertain whether this represents ocular fixation instability from disease or might result from the electronic characteristics of the recording apparatus. Similar pen movements have been noted at times in patients with Meniere's disease. Coarse flutter and opsoclonus were not found.

\section{B. Smooth Pursuit}

All patients had marked saccadic alteration of smooth pursuit movements, at times with superimposed gaze nystagmus (Fig. 3).

\section{Optokinetic Nystagmus}

OKN response to horizontal and vertical stimuli was grossly abnormal in all patients. Fig. 4 shows the ranges and mean values of slow component eye velocity for the horizontal and vertical stimuli, in both the patient population and a population of six

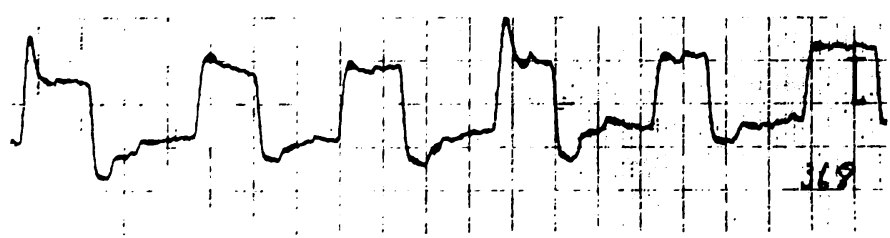

Figure 1-Vertical calibration movements. Pen movements from bottom to top of strip represent eye movements upward, and vice versa. Dysmetric overshoots on gaze downward alone. the pointed "overshoots" on gaze upward on first and fourth calibration excursions represent blink. normal twenty year old subjects. As stimulus speed increased, the mean eye velocity, initially low, declined still further in both horizontal and vertical directions. The quick phases of nystagmus when present were apparent, but there was a good deal of saccadic alteration of the slow component, much as in the pendulum tracking response.

\section{Gaze Tests}

Horizontal nystagmus was absent in all patients with eyes in the primary position, whether with eyes open or closed. One patient had downward beating vertical nystagmus in the primary position, enhanced by lateral gaze in both directions, with eyes open and closed. Two others had low velocity vertical nystagmus beating upward on gaze upward only, not enhanced by lateral gaze deviation, and only with eyes open.

Horizontal gaze nystagmus was present in all patients, bilateral in nine and unilateral in two. The nystagmus was found only with eyes open and was enhanced with increasing lateral gaze deviation up to $40^{\circ}$. Bilateral horizontal rebound nystagmus was observed in the two patients in whom the finding was sought.

In one patient, unilateral gaze nystagmus appeared only at $40^{\circ}$ gaze deviation to right, and in the right eye alone. One patient had right-beating horizontal nystagmus in the right eye alone on $30^{\circ}$ gaze deviation to right, and nystagmus to left in left eye alone on the same gaze deviation to left (Fig. 5). With these two exceptions, all
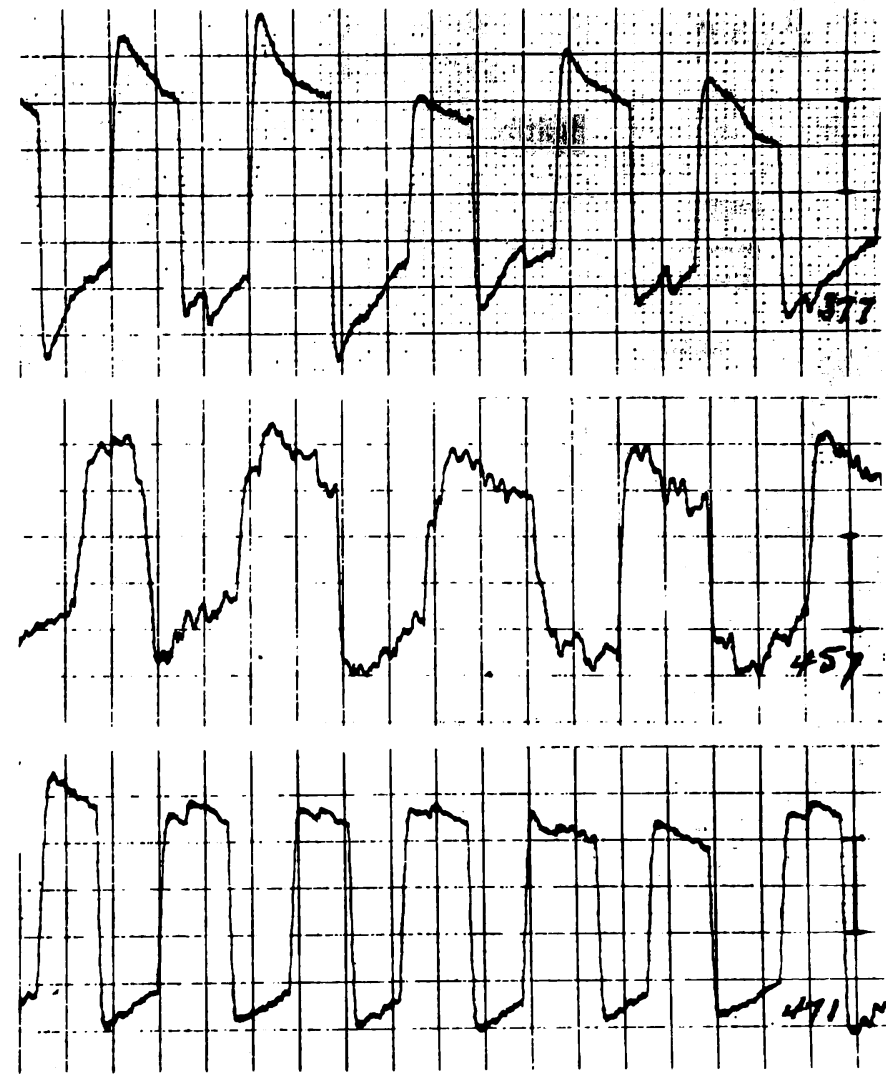

Figure 2-Horizontal calibration movements. Pen movements to top of strip represent eye movements to right; to bottom, left. Top strip: normal, smooth calibration tops and bottoms (fixation stability). Middle strip: rapid low amplitude oscillations (?fixation instability). Lower strip: very fine, very low amplitude oscillations, so common in this and other clinical material that it might represent either electronic or biological effect. 


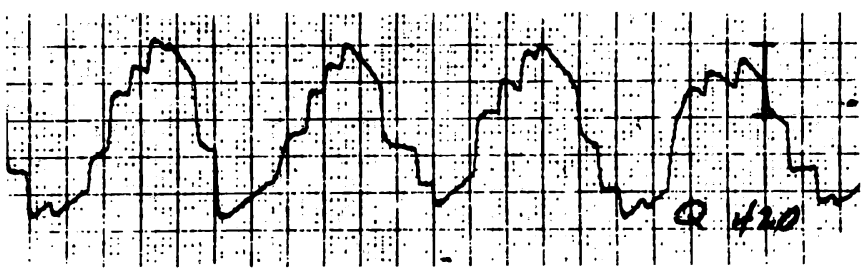

Figure 3-Saccadic alteration (cogwheeling) of horizontal pursuit movements.

patients had conjugate eye movements in the gaze tests.

\section{E. Caloric Tests}

All but one patient had normal primary caloric responses: direction of response appropriate to stimulus, peak values, and right/left percentage differences of maximum slow component velocity within normal limits (Barber and Stockwell, 1976). One woman, aged forty-two and the oldest patient of the eleven studied, had markedly reduced responses to bithermal stimuli. The single weak response to four irrigations resulted from stimulation of the left ear with water temperature $44^{\circ} \mathrm{C}$.

The caloric fixation index (Barber and Stockwell, 1976) was abnormal in all patients in at least one test. Each patient's maximum fixation index was recorded and the mean value for the entire group was 1.3

\section{F. Positions Test}

Significant positional nystagmus (Barber and Wright, 1973) was absent in all patients.

\section{DISCUSSION}

The cerebellum is concerned with control or modulation of eye movements. Considerable knowledge has been gained in recent years from studies in alert animals, especially monkeys. Ron and Robinson (1973) found that conjugate eye movements, mainly of the saccadic type, were evoked by stimulation of vermis lobules V - VII only and both saccades and smooth pursuit movements from the paravermian and more laterally placed areas of the hemispheres, crura I and II, and lobulus simplex. Nystagmus resulted from stimulation of the flocculus, nodulus, and uvula. Stimulation of other parts of the cerebellar cortex produced no eye the vermis".

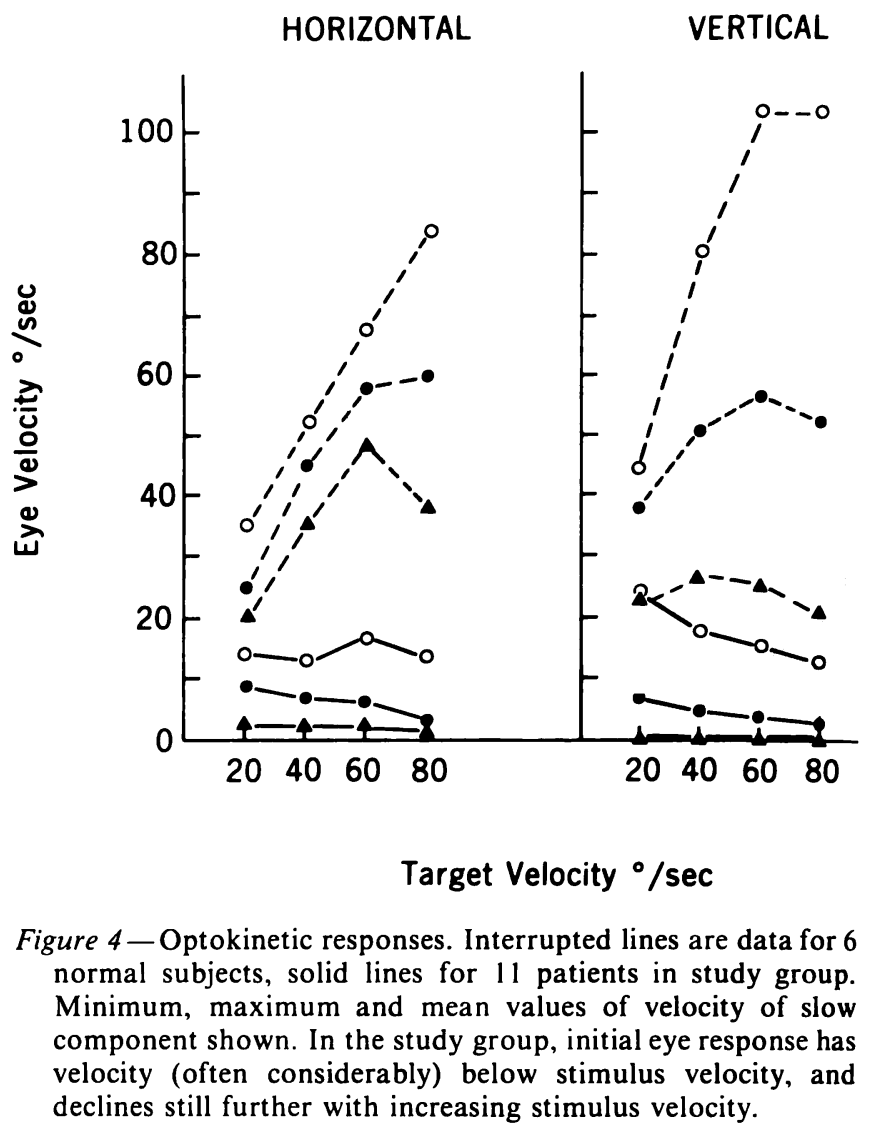

movements. However, stimulation of all the cerebellar nuclei evoked either or both saccades and smooth movements in different directions Precht (1975), in commenting on this work, noted that "saccades are probably the characteristic type of eye movements evoked by stimulation of

Further information has been obtained from study of the effects of cerebellar lesions on alert monkeys. After complete one-step ablation of the cerebellum, Westheimer and Blair (1973) found inability to maintain eccentric gaze, loss of smooth pursuit capacity when the animal was presented with a sinusoidally moving target, and marked reduction of maximal slow phase velocity of OKN. Unilateral cerebellectomy (Westheimer and Blair, 1974) caused constant drift of the eyes in the contralateral direction but no significant abnormality of saccadic movement or of the vestibulo-ocular reflex. These authors reasoned that since cerebellar lesions which cause centripetal drift also always produce defects in pursuit movements, the abilities to maintain eccentric gaze and to pursue smoothly must have a common origin.

Takemori and Cohen (1974) produced the same findings after unilateral and bilateral flocculectomy alone, together with direction-fixed positional nystagmus; while caloric nystagmus in darkness was unaffected by floccular destruction. Visual suppression of caloric nystagmus was lost or reduced when quick phases were directed toward the side of lesion after unilateral flocculectomy, and to both sides after bilateral flocculectomy. Takemori (1975) found that nodulus lesions also caused defective visual suppression of caloric nystagmus, but the effect was less marked and declined after about 45 days. Takemori and Suzuki (1977) reported similar findings after lesions of vermis, flocculus, and deep cerebellar nuclei in only with bilateral flocculus lesions. OKN responses were severely immonkeys and found gaze nystagmus 
paired after nodulus and flocculus lesions for a prolonged period. In five animals with bilateral flocculus lesions, downward vertical spontaneous nystagmus with rotational component persisted for seven months.

In the cat, Fernandez and Fredrickson (1964) found that nodulus stimulation caused reduced strength of caloric nystagmus and ablation enhancement of caloric nystagmus, as an effect of loss of the inhibitory influence of the cerebellum upon vestibular sensory input. In addition, unilateral lesions of flocculus and paraflocculus in some cats caused mainly direction-changing positional nystagmus, often paroxysmal, as did lesions of nodulus.

All our patients showed multiple oculomotor and vestibular abnormalities. All had marked impairment of smooth pursuit, OKN, and fixation suppression of caloric nystagmus. Most had amplitude defects of saccadic eye movements in the form of hypometric and/or hypermetric saccades in horizontal and/or vertical axes. All had bilateral or unilateral horizontal gaze nystagmus; horizontal rebound nystagmus was present in the two patients in whom the finding was sought, and downward beating vertical nystagmus was found in one.

Smooth pursuit and OKN defects were striking in all patients. The eye movements were conjugate and, despite the fact that Bouchard et al (1978) found saccadic pursuit on clinical examination in the horizontal axis only, defective $\mathrm{OKN}$ patterns were recorded about equally in horizontal and vertical axes. The velocity of the quick component of the OKN seemed normal.

Takemori and Cohen's (1974) Fig. 2 (b) and (c), and Takemori and Suzuki's (1977) Fig. 3 (a) and (b) show low velocity $\mathrm{OKN}$ in monkeys with bilateral flocculectomy that is remarkably similar to the $\mathrm{OKN}$ findings in our patients (Fig. 4). Pursuit and OKN abnormalities were as marked in the younger as the older patients, hence could not be taken as an index of disease progression in our study sample.

Defects of saccadic eye movement may take the form of one or more of reduced latency, reduced velocity, or impaired control of amplitude (hypometric or hypermetric saccades). The evidence in the literature on the anatomical substrate for these features is inconclusive. Thus, saccadic velocities were within normal range in
Westheimer and Blair's (1973) bilaterally cerebellectomized monkeys and in five patients with late onset, dominantly inherited cerebellar ataxia reported by Zee et al (1976). Baloh et al (1975) described the ocular motor findings in a group of fifteen patients with spinocerebellar degeneration, finding reduced saccade velocity in nine, mainly those with classic Friedreich's ataxia and diffuse brainstem-cerebellar disease. However, these authors also found definite saccadic slowing in two patients of four with "pure" cerebellar atrophy. Zee, Optican et al (1976) found slowed horizontal saccades in two patients with spinocerebellar degeneration, each of whom had prominent brainstem features in addition to cerebellar symptoms and signs. Wadia and Swami (1971) found marked reduction of fast eye movement speeds in horizontal and vertical axes, without gaze palsy, in a genetic form of spinocerebellar degeneration apparently confined to India. Perhaps it is fair to say that amplitude defects of saccadic movement occur in cerebellar

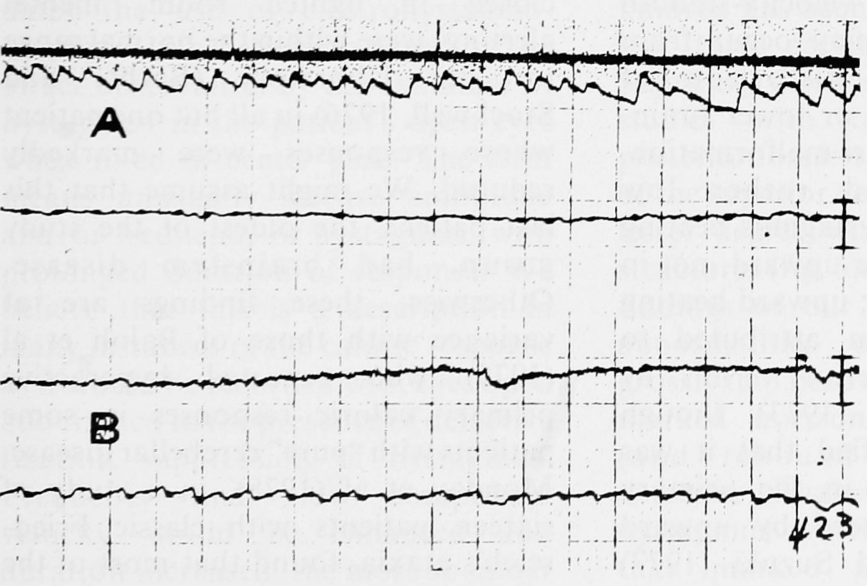

Figure 5-Probable bilateral internuclear ophthalmoplegia. A gaze $30^{\circ}$ to right, top strip monocular leads right eye, lower is left eye. B - gaze $30^{\circ}$ to left, top strip right eye, lower is left eye. Movement of the eyes from the primary to lateral positions not recorded.

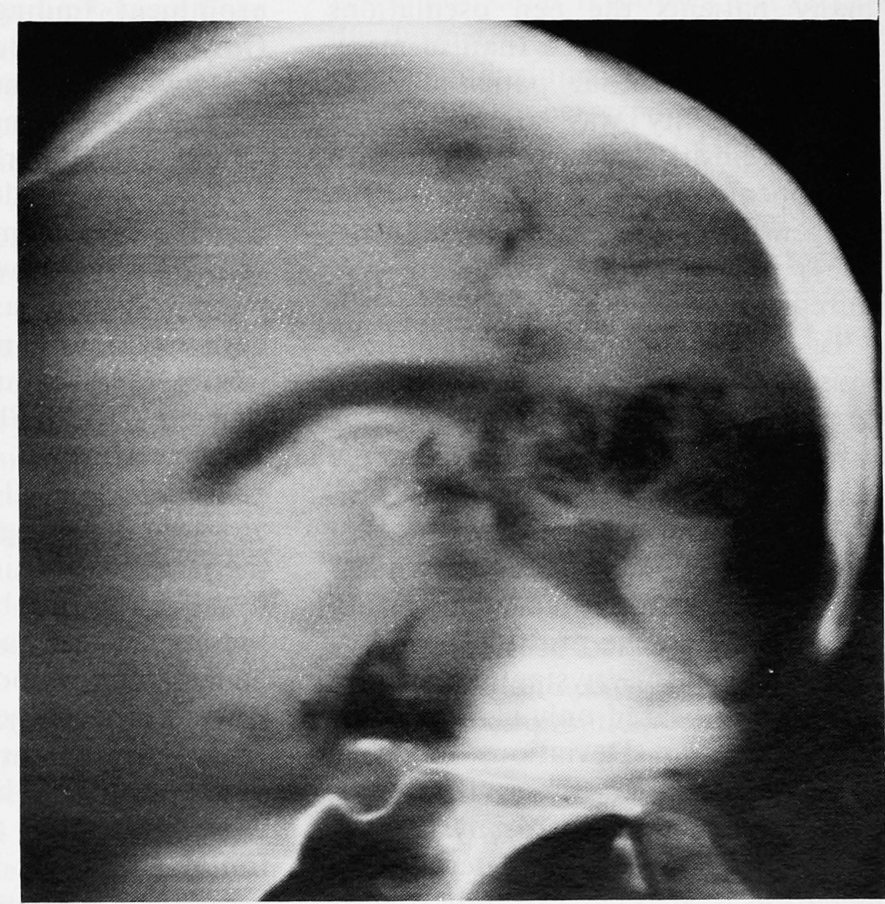

Figure 6-Sagittal tomography of the posterior fossa showing extreme atrophy of the superior vermis in a case of familial spastic ataxia. 
vermis atrophy, but reduced velocity may occur from lesions of either cerebellum or brainstem.

Amplitude control of saccades was defective in most of our patients, resulting in hypometric and/or hypermetric rapid eye movements between two fixed targets. In the vertical axis, hypermetric saccades occurred only on downward gaze, as in the patients studied by Zee et al (1976). Lesser et al (1973) reported a similar finding, predominantly on eye movement from gaze upward to the primary position. In our material, oscillations after overshoot correction (Higgins and Daroff, 1966) were unobtrusive or absent.

We were unable to identify slowing of saccades in horizontal or vertical axes from visual inspection of our records, but found it difficult to make a definitive judgement on this matter because of technical limitations of the equipment.

The saccade characteristics in our patients suggest greater involvement of cerebellum than brainstem.

Some degree of ocular fixation instability was present, characterized by high frequency, low amplitude, horizontal eye movements, though in many patients the pen oscillations were no more marked than in many other non-cerebellar patients. Fixation instability was absent in the primary position of gaze, whether with eyes open or closed. Square wave jerks (Gegenrucke-Jung and Kornhuber, 1964) with eyes open or closed were infrequent.

In our patients, horizontal nystagmus was absent with eyes in the primary position, though faint downward beating vertical nystagmus was present in one. The horizontal jerk nystagmus observed was present in lateral gaze positions varying from $20^{\circ}$ to $40^{\circ}$ and was enhanced by increasing deviation from the primary position. In several cases, nystagmus in one direction appeared only at $40^{\circ}$ lateral gaze deviation. Deviations of lesser degree failed in these to evoke nystagmus. In other words, nystagmus appearing on extreme lateral gaze deviation is at times certainly due to disease (as in our patients), not due to physiologic or end-point effect. Lateral gaze deviation of lesser degrees would have failed entirely to evoke this useful physical sign of disease.

Among other functions, the cerebellum is concerned with maintenance of eccentric gaze (Westheimer and Blair, 1974). After cerebellectomy in primates, the eyes move to one side with a saccade and drift back towards midline, when another saccade returns the eye to the lateral position and so on. Typical gaze paretic nystagmus is the result. Robinson (1974) postulates that all horizontal saccades are initiated in response to bursts of electrical activity from a neural integrator located in the paramedian pontine reticular formation, and that this is an inherently "leaky" neutral integrator so that the eyes drift from lateral gaze back to the mid position unless prevented from doing so by the cerebellum. Somehow the cerebellum improves the performance of the "leaky" integrator so that the eyes will not return slowly to midline from a lateral position. If the cerebellum is defective (as in our patient population), the eyes drift back from the position of lateral deviation, saccades interrupt this drift periodically, and the result is gaze nystagmus.

Vertical nystagmus was not a prominent finding in our patients. Only one patient had downbeat nystagmus, enhanced by lateral gaze, though this finding was present in all 12 patients described by Zee et al (1976). Zee et al (1974) considered downbeat nystagmus as a component of a defective down velocity-smooth pursuit system, as may occur from compression and distortion of vestibulo-cerebellum or lower brainstem in Arnold-Chiari malformation. Two patients had rather low amplitude vertical nystagmus beating upward only on gaze upward, not in the primary position; upward beating nystagmus has been attributed to lesions of the anterior vermis by Daroff and Troost (1973), though these authors specified that it was likely to be coarse in the primary position and enhanced by upward gaze. Takemori and Suzuki (1977) found consistent vertical downward spontaneous nystagmus after bilateral flocculus destruction in monkeys. Lesions of lower and midline cerebellum, therefore, may be implicated in vertical nystagmus, in addition to the known association of downward beating vertical nystagmus with lesions of lower medulla or medullo-cervical region (Cogan, 1968).

None of our patients had significant positional nystagmus when tests were conducted with eyes closed and effective mental alerting. This was surprising in the light of the findings of Takemori and Cohen (1974) and Fernandez and Fredrickson (1964), who found different forms of nystagmus, including paroxysmal, after partial unilateral flocculectomy in alert monkeys and unilateral nodulus ablation in cats. Probably the reason for the disparity in these observations is to be found in the differing test conditions, our patients with eyes closed and the other authors' animals eyes open. Clinical observations on positional nystagmus with eyes open were not made in our patients. Maekawa and Simpson (1972) showed a direct visual influence on the Purkinje cells of the vestibulocerebellum in the rabbit and cat through a neuronal pathway consisting of the accessory optic tract, central tegmental tract and inferior olive. Perhaps the input function of this system, or a lesion of its neuronal pathway in association with a vestibulo-cerebellar defect, might have an important influence on positional nystagmus.

Primary caloric responses (eyes closed in lighted room, mental alerting) were within the normal range for our laboratory (Barber and Stockwell, 1976) in all but one patient whose responses were markedly reduced. We might assume that this last patient, the oldest of the study group, had brainstem disease. Otherwise, these findings are at variance with those of Baloh et al (1975) who reported hyperactive primary caloric responses in some patients with "pure" cerebellar disease. Monday et al (1978), in a study of sixteen patients with classic Friedreich's ataxia, found that most of the patients had normal caloric responses, while four had bilateral caloric reduction and one, unilateral. The difference between our findings and those of Baloh et al (1975) may be 
explained in part by differing normal values and test procedure, but Dichgans and Jung (1975) note that in human cerebellar lesions hyperresponsiveness appears to be rare, and that most cerebellar atrophies show normal vestibular responses.

On the other hand, defective fixation suppression of caloric nystagmus was present in all patients, and markedly in a few. This finding was striking and consistent, and corresponded so closely to the same observation in bilaterally flocculectomized monkeys (Takemori and Cohen, 1974; Takemori, 1975; Takemori and Suzuki, 1977) as to make our patients in this respect indistinguishable from these workers' experimental animals. Visual conditions have a profound effect on vestibular nystagmus. Baloh et al (1975) found in one patient with parenchymal cerebellar atrophy that eye closure during caloric-induced nystagmus completely inhibited the nystagmus. "The phenomenon was clearly due to eye closure and not loss of fixation or retinal input since the nystagmus remained brisk with plus 30 lenses and in a darkened room". In the same patient eyes-open caloric nystagmus was not inhibited. The explanation for these observations is not apparent, but we mention them to draw attention to the necessity of specifying test conditions carefully in reporting caloric results. The term "hyperactive" caloric response antedates the use of electronystagmography: it is a definition based on the direct observation by the examiner of nystagmus in the patient's open eyes when fixed in center gaze. The term means unusually intense amplitude and/or frequency of nystagmus, with prolonged duration of response. We believe that this is a description in many instances of the caloric response as it would be recorded with eyes open and fixated in the presence of defective fixation suppression of nystagmus. Frequency and slow component velocity would be enhanced and duration increased, the more so under conditions of visual observation.

Caloric hyperresponsiveness occurs at times in regular clinic patients (not the present study group), perhaps related to nervousness, but in these fixation suppression of the nystagmus is evident and normal. We have also seen a patient with meningioma of the lateral sinus markedly indenting one cerebellar hemisphere whose eyesclosed caloric responses were hyperactive in each direction; this patient had also defective visual suppression of the nystagmus. In light of these comments, perhaps we should reconsider the criteria for "hyperactivity" of caloric response in cerebellar lesions.

Our study presented us with a cornucopia of oculomotor and vestibular abnormalities though for the most part these were of a quite consistent type. It is interesting to attempt to locate the lesions responsible for these findings.

Zee et al (1976) note correspondence of the clinical pattern of their group of patients with hereditary cerebellar ataxia to five reports of other authors in which post-mortem examination of the brains was carried out. In these, the most consistent abnormality was a highly selective atrophy of the cerebellar cortex, with varying degrees of neuronal loss within the deep cerebellar nuclei and inferior olive. The remainder of the nuclei and fiber tracts within the brainstem showed no pathological alterations. Our patients were derived from an autosomal recessive pattern of inheritance, unlike those of Zee et al (1976), and to date no pathological material from this kindred has been obtained. Nevertheless, three patients with CharlevoixSaguenay disease have undergone air studies with tomography of the posterior fossa: a very marked atrophy of the superior vermis was shown, to a lesser degree within other cerebellar structures (fig. 6). The most prominent findings of our study were marked abnormalities of smooth pursuit, grossly impaired optokinetic response, marked horizontal gaze nystagmus (and rebound nystagmus), and defective visual suppression of caloric nystagmus which lead us to believe that marked and often bilateral degeneration of at least the vestibulocerebellum, especially the flocculus or connections with brainstem, is probable in our patients. Downbeat vertical nystagmus and downward hypermetric saccades may point to a lesion in the same area. Horizontal saccadic amplitude defects were common, fixation instability and upbeat vertical nystagmus uncommon, but taken together these findings indicate vermis disease.

Cerebellar diseases often involve brainstem structures as well. As Dichgans and Jung (1975) note, "Even the systematic cerebellar atrophies ... may involve brainstem nuclei, at least in their later stages". Thus, one of our patients, the oldest of the group, had considerably reduced caloric response bilaterally. Another had probably bilateral medial longitudinal fasciculus involvement. We take these findings as clear evidence of brainstem abnormality in these two patients.

We cannot be certain that the brainstem is unaffected in our other patients, short of pathological confirmation. Nevertheless, our observations are generally consistent with the comment of Zee et al (1976) that their observations and those of Hood et al (1973) and Baloh et al (1975) ... "suggest that, in combination, defective pursuit, gaze paretic and rebound nystagmus, enhanced vestibulo-ocular responses and saccadic dysmetria are highly suggestive of cerebellar dysfunction". The matter of "vestibular hyperresponsiveness" has been discussed above. Dichgans et Jung (1975) include among valuable signs seen exclusively in cerebellar patients the coincidence of normal or increased vestibulo-ocular responses with impaired ocular pursuit and optokinetic nystagmus.

Combining the diagnostic criteria of these authors, it seems likely that the lesions responsible for the vestibular and ocular motor findings recorded by electronystagmography in our patients with Charlevoix-Saguenay disease are to be located mainly within the cerebellum, especially the vestibulo-cerebellum and vermis.

\section{ACKNOWLEDGEMENT}

This study was supported by a grant from l'Association Canadienne de l'Ataxie de Friedreich. The authors thank Raymonde Bergeron and Luc Verret for their skilled technical assistance. 


\section{REFERENCES}

BALOH, R. W., KONRAD, H. R. and HONRUBIA, V. (1975). Vestibulo-ocular function in patients with cerebellar atrophy. Neurol., 25, 160-168.

BARBER, H. O., WRIGHT, G. and DEMANUELE, F. (1971). The hot caloric test as a clinical screening device. Arch. Otolaryngol., 94, 335-337.

BARBER, H. O. and WRIGHT, G. (1973). Positional nystagmus in normals. Adv. OtoRhino-Laryng., 19, 276-285.

BARBER, H. O. and STOCKWELL, C. W. (1976). Manual of Electronystagmography. The C. V. Mosby Co., St. Louis (Publisher).

BOUCHARD, J. P., BARBEAU, A.,BOUCHARD, R. and BOUCHARD, R. W. (1978). Autosomal recessive spastic ataxia of Charlevoix-Saguenay. Can. J. Neurol. Sci., 5, 61-69.

COGAN, D. G. (1968). Down-beat nystagmus. Arch. Ophthal., 80, 757-768.

DAROFF, R. B. and TROOST, B. T. (1973). Upbeat nystagmus. J.A.M.A., 225, 312.

DICHGANS, J. and JUNG, R. (1975). Oculomotor abnormalities due to cerebellar lesions. In Basic Mechanisms of Ocular 'Motility and Their Clinical Implications, eds. G. Lennerstrand and P. Bach-y-Rita. Pergamon Press, 281-298.

FERNANDEZ, C. and FREDRICKSON, J. M. (1964) - Experimental cerebellar lesions and their effect on vestibular function. Acta Otolaryngol., Suppl. 192, 5262.
HIGGINS, D. C. and DAROFF, R. B. (1966). Overshoot and oscillation in ocular dysmetria. Arch. Ophthal., 75, 742-745.

HOOD, J. D., KAYAN, A. and LEECH, J. (1973). Rebound nystagmus. Brain, 37, 466488.

JUNG, R. and KORNHUBER, H. H. (1964). Results of electronystagmography in man: The value of optokinetic, vestibular, and spontaneous nystagmus for neurological diagnosis and research. In Bender, M.B. (ed.) The Oculomotor System, New York, Harper and Row Publishers Inc., 428-482.

LESSER, R. L., SMITH, J. L., LEVENSON, D. S. and SUSAC, J . O. (1973). Vertical ocular dysmetria. Am. J. Ophthal., 76; 208211.

MAEKAWA, K. and SIMPSON, J. I. (1972). Climbing fiber activation of Purkinje cells in the floculus by impulses transferred through the visual pathway. Brain Research, 245251.

MONDAY, L. A., LEMIEUX, B., ST.VINCENT, H. and BARBEAU, A. (1978). Clinical and electronystagmographic findings in Friedreich's ataxia. Can. J, Neurol. Sci., 5, 71-73.

PRECHT, W. (1975). Cerebellar influences on eye movements. In Basic Mechanisms of Ocular Motility and Their Clinical Implications, eds. G. Lennerstrand and P. Bach-y-Rita. Pergamon Press, 261-280.

ROBINSON, D. A. (1974). The effect of cerebellectomy on the cat's vestibulo-ocular integrator. Brain Research, 71, 195-207.

RON, S. and ROBINSON, D. A. (1973). Eye movements evoked by cerebellar stimulation in the alert monkey. J. Neurophysiol., 36, 1004-1022.
TAKEMORI, S. and COHEN, B. (1974). Loss of visual suppression of vestibular nystagmus after flocculus lesions. Brain Research, $72,213-224$

TAKEMORI, S. (1975). Visual suppression of vestibular nystagmus after cerebellar lesions. Ann. Otol., Rhinol. and Laryngol., 84, 318326.

TAKEMORI, S. and SUZUKI, M. (1977). Cerebellar contribution to oculomotor function. ORL, 39, 209-217.

WADIA, N. H. and SWAMI, R. K. (1971). A new form of heredo-familial spinocerebellar degeneration with slow eye movements (nine families). Brain, 94, 359-374.

WESTHEIMER, G. and BLAIR, S. M. (1973). Oculomotor defects in cerebellectomized monkeys. Invest. Ophthal. 12, 618-621.

WESTHEIMER, G. and BLAIR, S. M. (1974). Functional organization of primate oculomotor system revealed by cerebellectomy. Exp. Brain Res. 21, 463-472.

ZEE, D. S., FRIENDLICH, A. R. and ROBINSON, D. A. (1974). The mechanism of downbeat nystagmus. Arch. Neurol., 30, 227-237.

ZEE, D. S., YEE, R. D., COGAN, D. G., ROBINSON, D. A. and ENGEL, W. K. (1976). Ocular motor abnormalities in hereditary cerebellar ataxia. Brain,99, 207234.

ZEE, D. S., OPTICAN, L. M., COOK, J. D., ROBINSON, D. A. and ENGEL, W. K. (1976). Slow saccades in spinocerebellar degeneration. Arch. Neurol., 33, 243-251. 